\title{
USO DE TÉCNICAS DE APO COM CRIANÇAS EM UM PROGRAMA DE EDUCAÇÃO AMBIENTAL
}

\author{
DELABRIDA, Zenith Nara Costa \\ Universidade Federal de Sergipe, e-mail: zdelabrida@gmail.com \\ ALMEIDA, Camila Couto de \\ Universidade Federal de Sergipe, e-mail: camilacouto96@gmail.com \\ FONTES, Anna Beatriz da Silva \\ Universidade Federal de Sergipe, e-mail: abeatrizfontes123@gmail.com \\ LEAL, Rose Milena dos Anjos \\ Universidade Federal de Sergipe, e-mail: rose.rmaleal@gmail.com
}

\begin{abstract}
RESUMO
É necessário preparar as próximas gerações para os desafios ambientais atuais e vindouros e a educação ambiental parece ser a principal alternativa. Aqui apresenta-se um programa de educação ambiental com base nos conhecimentos de psicologia ambiental, em técnicas de Avaliação Pós-ocupação (APO) e na teoria das habilidades sociais (THS). O trabalho foi desenvolvido a partir da conciliação entre pesquisa e extensão, iniciado em 2013 e em fase atual de conclusão. A proposta do projeto foi operacionalizada em 10 encontros com crianças que acontecem no espaço da escola com a mediação do professor(a). É possível concluir que as técnicas de APO e habilidades sociais podem ser usadas como estratégia para entender o ambiente físico e social com crianças.
\end{abstract}

Palavras-chave: Avaliação Pós-ocupação, Habilidades Sociais, Psicologia Ambiental.

\begin{abstract}
It is necessary to prepare the next generations for the actual and coming environmental challenges and then environmental education seems to be the main alternative.. It is here presented an environmental education program based in knowledges as environmental psychology, post-occupancy evaluation and the social skills theory. The work was developed from extension and scientific initiation researches which began in 2013 and are currently in conclusion. The proposal of the project was made operational in 10 encounters with children that happen at school with teacher's mediation. It is possible to conclude that the post-occupancy evaluation techniques and the social skills can be used as a strategy to understand the physical and social environment with children.
\end{abstract}

Keywords: Post-Occupancy Evaluation, Social Skills, Environmental psychology.

\section{INTRODUÇÃO}

A educação ambiental parece ser a principal alternativa para o desenvolvimento de novos valores associados às questões ambientais (KOPNINA, 2014). Assim, o ambiente escolar se tornou o local de acesso ao público infantil (ARDOIN et al 2017; CHARATSARI; LIOUTAS, 2017; KARPUDEWAN; KEONG, 2012), permitindo a formação de cidadãos capazes de estabelecer uma relação pessoa-ambiente mais amigável e sustentável.

DELABRIDA, Z. N. C.; ALMEIDA, C. C.; FONTES, A. B. S.; LEAL, R. M. A. Uso de técnicas de APO com crianças em um programa de educação ambiental. In: SIMPÓSIO BRASILEIRO DE QUALIDADE DO PROJETO NO AMBIENTE CONSTRUÍDO, 6., 2019, Uberlândia. Anais... Uberlândia: PPGAU/FAUeD/UFU, 2019. p. 1431-1439. DOI https://doi.org/10.14393/sbqp19128. 
Partiu-se da premissa de que o espaço físico de uma escola é um ambiente complexo que pode permitir o entendimento da relação pessoa-ambiente tanto da perspectiva do ambiente construído quanto da perspectiva do ambiente natural. Entendendo esse ambiente como 0 invólucro onde atividades de formação das crianças acontecem, este poderia ser usado como treino para a relação com os demais ambientes que a criança frequenta. Ao focar no ambiente físico estamos tratando do que está à nossa volta, como o ambiente nos afeta e como afetamos o ambiente (GÜNTHER; ROZESTRATEN, 1993; SOMMER, 2014).

Segundo a lei brasileira $n^{\circ} 12.608$, de 10 de abril de 2012, os currículos do ensino fundamental e médio devem incluir a educação ambiental de forma integrada aos conteúdos obrigatórios, como um tema transversal. Nesse contexto, o objetivo geral do projeto de pesquisa foi desenvolver uma proposta de intervenção em educação ambiental baseada em conhecimentos científicos que pudessem auxiliar professores a introduzir a educação ambiental, utilizando o ambiente físico da escola como estratégia didática. Portanto, neste artigo é apresentado como os conhecimentos de psicologia ambiental, em técnicas de Avaliação Pós-ocupação (APO) e na teoria das habilidades sociais (THS) foram transformados em um programa de educação ambiental.

\section{LITERATURA SOBRE O TEMA}

Para a psicologia ambiental, a solução dos problemas ambientais de nossas sociedades passa pela investigação de como as pessoas afetam e são afetadas pela qualidade do seu entorno (CASTRO, 2010). Nesta perspectiva, a educação ambiental é vista como uma forma de promover trocas consistentes de conhecimentos e mudança de atitudes em direção a comportamentos sustentáveis ambientalmente. É enfatizado o desenvolvimento da capacidade de pensar de forma crítica, ética e criativa no enfrentamento dos desafios da sustentabilidade bem como a capacidade de agir individualmente e coletivamente em prol de uma relação pessoaambiente mais amigável (KOPNINA, 2014; WALS et al., 2014).

No entanto, a inserção das temáticas ambientais de maneira transversal nos currículos escolares, sem a devida sequência, pode não ser suficiente para que os alunos tenham comportamentos ambientalmente responsáveis (POL, 2009), o que reforça que a educação ambiental na escola deve ser feita de maneira criteriosa, cuidadosa e no momento adequado. Para que 0 conhecimento faça sentido a quem está escutando, lendo, discutindo é necessário que ele seja contextualizado (FREIRE, 1997). E, em função da complexidade dos problemas ambientais, não pode estar alheia aos conhecimentos científicos vigentes. Ao contrário, deve usar o conhecimento científico como forma de capacitar as pessoas para agir na solução desses problemas (MERENLENDER et al., 2016).

Desta forma, considerando o processo de aquisição de conhecimento ambiental via educação ambiental, objetivou-se desenvolver um programa de educação ambiental que, além da mera transmissão de informações a respeito das questões ambientais, ensinasse conhecimento científico às crianças seguindo o modelo de ciência cidadã e concebesse a educação ambiental como promotora de habilidades para ações individuais e coletivas. Para tanto, utilizou-se do ensino de um conjunto de técnicas de APO e de conceitos da Teoria das Habilidades Sociais a seguir apresentadas. 
A avaliação pós-ocupação (APO) "é um processo interativo, sistematizado e rigoroso de avaliação de desempenho do ambiente construído, passado algum tempo de sua construção e ocupação" (RHEINGANTZ et al., 2009, p. 16). Assim, é realizado um diagnóstico dos aspectos funcionais positivos e negativos, servindo de feedback sobre a qualidade do planejamento e da construção - analisando, por exemplo, o conforto ambiental, a relação custobenefício da manutenção e a relação entre o ambiente construído e o comportamento humano (ORNSTEIN, 2005). A APO tem uma função de promover uma interface de quem usa o ambiente físico com quem gerencia o ambiente físico (FERREIRA, 2006; FRANÇA, 2011). Essa mediação é fundamental para que sejam feitos ajustes na construção e no uso daquele espaço. Além disso, a investigação do ambiente físico que faz parte do dia-a-dia dos indivíduos tem impacto no significado atribuído aos mesmos, à um senso de lugar (KUDRYAVTSEV; STEDMAN; KRASNY, 2012) e que em última instância também vai se relacionar com a identidade do próprio indivíduo, com o senso que se tem da sua existência e o sentido que se dá a ela.

No presente trabalho foram utilizadas três técnicas: Walkthrough, Poema dos Desejos e Matriz de Descobertas, seguindo RHEINGANTZ et al. (2009). Walkthrough envolve um passeio com uma entrevista. Essa técnica possibilita a identificação descritiva dos aspectos negativos e positivos dos ambientes analisados, permitindo um (re)conhecimento do ambiente tanto pelo pesquisador quanto pelo usuário daquele espaço. Neste caso, usamos o tipo grupo de participantes: estudantes, professores, técnicos que transitam pelo espaço da escola e vão apontando os pontos positivos e os pontos negativos, além de serem discutidas ações de melhoria ou recomendações. Quem está responsável pela atividade (professor(a) ou estudante) faz as anotações e registra em fotos.

Poema dos Desejos é um instrumento de pesquisa que permite ter acesso aos desejos e demandas relativos ao espaço estudado. O ponto de partida é uma sentença: "Eu gostaria que meu ambiente...". Sua elaboração é simples bem como sua aplicação. O participante pode escrever ou desenhar. Sendo assim, é aplicável para indivíduos de diferentes idades. É uma técnica que amplia o entendimento das características e funções daquele espaço e permite que o participante exponha o seu imaginário.

Matriz de descobertas é utilizada, principalmente, para identificar as adaptações e improvisações no uso do espaço e como as atividades são viabilizadas dado aquele espaço. É utilizada a planta baixa do ambiente como referência para a observação e identificação das descobertas sobre o espaço. A planta baixa, como desenho estruturado do ambiente, auxilia na identificação das características físicas e dos usos feitos. É criado um formulário de registro que pode ser preenchido por quem está conduzindo a atividade com o auxílio dos usuários daquele espaço evidenciando o aspecto visual das informações a serem coletadas.

Deve-se ressaltar que a literatura aponta a necessidade de se realizar este tipo de investigação em escolas brasileiras (ORNSTEIN, 2005). Com o objetivo de contribuir para esta área, além de promover o pensamento crítico acerca das condições do ambiente do entorno dessas escolas, a APO pode ser considerada um instrumento para a realização de uma pesquisa-ação já que é baseada em um aspecto teórico, mas que se encaixa bem em uma intervenção, na qual os atores sociais têm um papel ativo na condução da pesquisa (BALCAZAR et al., 1998). 
As habilidades sociais (HS) são um conjunto de habilidades que estão associadas ao desempenho social (CABALLO, 2006; DEL PRETTE; DEL PRETTE, 1996; LOPES et al., 2015). Quanto maior forem as habilidades sociais, maior a possibilidade de se observar um desempenho social competente, bemsucedido (CABALLO, 2006; DEL PRETTE, 1996). Por vezes, a aplicação dos conhecimentos técnicos demanda muito mais de uma competência social para lidar com o contexto social que exclusivamente da habilidade técnica de executar a tarefa. Da mesma forma, no ambiente acadêmico, as habilidades sociais se mostram críticas por permitir que se lide de uma maneira melhor com as demandas dos diferentes interlocutores e contextos (LOPES et al., 2015).

Dentre as habilidades sociais que podem favorecer a competência social, a assertividade é um estilo de comunicação que permite melhorar o desenvolvimento pessoal e as relações sociais das crianças por estar baseada na afirmação dos próprios direitos, na expressão de pensamentos, crenças e sentimentos, sem violar o direito dos outros (MOREIRA, 2016). Essa habilidade pode permitir que as crianças coloquem em prática novos conhecimentos aprendidos, já que, inversamente, a literatura mostra que as crianças mais agressivas com seus pares possuem um rendimento escolar mais baixo em comparação com as crianças menos agressivas (MOREIRA, 2016).

Apesar do ensino formal focar nos conteúdos obrigatórios, o desenvolvimento emocional e interacional é igualmente importante. Tarefas com qualquer grau de complexidade podem exigir habilidades de negociação com os outros (professores, colegas, pais) e consigo mesmo para se manter o empenho na sua realização. Portanto, o desempenho acadêmico não dependente somente da capacidade de aquisição do conhecimento, mas também da capacidade emocional e das habilidades para a interação interpessoal (CIA; BARHAM, 2009).

Concluindo, as tarefas propostas para as crianças no presente trabalho envolveram os três pontos tocados: aquisição de conhecimento sobre o ambiente baseado em técnicas de APO e psicologia ambiental bem como técnicas para o desenvolvimento de habilidades sociais. Sendo assim, oferecer um pequeno treino de habilidades sociais é suportado pela literatura como um facilitador do engajamento das crianças nas atividades, aumentando a possibilidade do seu sucesso que foi apresentado em conjunto com os conhecimentos científicos.

\section{METODOLOGIA}

Participaram do estudo 4 escolas, atingindo cerca de 130 estudantes residentes em Aracaju e região metropolitana, cursando $06^{\circ}$ ano do Ensino Fundamental e $1^{\circ}$ ano do Ensino Médio.

A intervenção foi elaborada a partir de pesquisas bibliográficas usando como descritores a literatura que relaciona a educação ambiental e psicologia ambiental, embasando-se nas técnicas de Avaliação Pós-ocupação e no Treino de Habilidades Sociais. Não foi objetivo do projeto de pesquisa aplicar todo o ciclo de uma APO ou de um treinamento de assertividade, mas aplicar alguns de seus elementos que contemplassem um conhecimento mínimo de alguns aspectos descritos abaixo. Seguiu-se a perspectiva da pesquisa-ação para a qual a prática e a teoria devem estar interligadas (DELABRIDA, 2011). Antes da apresentação do projeto, realizava-se uma intervenção artística com 
fotos do ambiente físico da escola a fim de despertar a atenção e a curiosidade das crianças. Em seguida, apresentava-se a proposta do trabalho nas turmas. Os alunos que se interessavam pelo projeto passavam a ir em turno contrário ao das aulas ou em horários regulares cedidos pelos professores. Dava-se início aos 10 encontros, cada um com duração entre 50 minutos à 1 hora. Está descrito no Quadro 1 o procedimento completo implementado nas escolas.

Quadro 1 - Procedimento completo do Programa de Educação Ambiental

\begin{tabular}{|c|c|c|}
\hline Fase & Encontro & Objetivo \\
\hline \multirow{3}{*}{ Fase Preparatória } & $\begin{array}{l}\text { Secretaria de } \\
\text { Educação do Estado } \\
\text { de Sergipe (SEED) }\end{array}$ & $\begin{array}{l}\text { Acesso às escolas estaduais do ciclo básico que tenham } \\
\text { turmas do 60. ano nas quais a faixa etária de referência } \\
\text { é } 11 \text { anos. }\end{array}$ \\
\hline & Nas escolas & $\begin{array}{c}\text { Contato a direção das escolas autorizadas pela SEED } \\
\text { para organização das atividades. }\end{array}$ \\
\hline & $\begin{array}{l}\text { Intervenção no } \\
\text { ambiente físico das } \\
\text { escolas }\end{array}$ & $\begin{array}{c}\text { Atrair a atenção das crianças para o ambiente físico da } \\
\text { escola }\end{array}$ \\
\hline \multirow{10}{*}{ Intervenção } & 10. Dia & $\begin{array}{c}\text { Construção dos óculos do saber e orientação a respeito } \\
\text { do projeto }\end{array}$ \\
\hline & 20. Dia & Instrumento para registro das atividades do programa. \\
\hline & 3o. Dia & $\begin{array}{l}\text { Aplicação da técnica do walkthrough e Poema dos } \\
\text { Desejos nas crianças participantes do programa }\end{array}$ \\
\hline & 40. Dia & $\begin{array}{c}\text { Apresentação das três técnicas de APO (Walkthrough, } \\
\text { Poema dos Desejos e Matriz de Descobertas) }\end{array}$ \\
\hline & 5o. Dia & Conceitos de Psicologia Ambiental \\
\hline & 60. Dia & Estilos de comunicação (assertivo, agressivo e passivo) \\
\hline & 7o. Dia & $\begin{array}{c}\text { Expressão verbal } \\
\text { Quiz de revisão das atividades }\end{array}$ \\
\hline & 80. Dia & $\begin{array}{c}\text { Parte prática: aplicação das técnicas de APO pelas } \\
\text { crianças }\end{array}$ \\
\hline & 90. Dia & Organização dos dados e da apresentação final \\
\hline & 100. Dia & $\begin{array}{c}\text { Encerramento com apresentação pública dos } \\
\text { resultados do projeto }\end{array}$ \\
\hline
\end{tabular}

Fonte: Autores (2018)

As atividades desenvolvidas nos 10 encontros variam entre atividades com um conteúdo teórico maior e atividades com um conteúdo lúdico maior. Essa alternância favorece o interesse das crianças, já que as tarefas mais lúdicas possuem um grau de dificuldade menor que as tarefas mais teóricas.

Os três aspectos teóricos que embasaram o projeto aparecem nos conteúdos das atividades propostas com as crianças para promover a educação ambiental voltada para o ambiente físico da escola. No 70 encontro é feito um Quiz para revisão dos conceitos aprendidos até então. Essa atividade mostrou que as crianças tinham ideia do que havia sido discutido, mas era necessário esse momento de revisão para a solidificação dos conhecimentos possibilitando implementar as demais atividades do programa.

O projeto foi aprovado pelo Comitê de Ética em Pesquisas com Seres Humanos da Universidade Federal de Sergipe (CAAE: 51 149315.2.0000.5546). Além disso, obteve a aprovação da Secretaria de Estado da Educação de 
Sergipe. Foram assinados os termos de consentimento livre e esclarecido pelos pais e de assentimento pelas crianças bem como pelos diretores das escolas.

\section{RESULTADOS}

De maneira geral, observou-se que os 10 encontros são suficientes para: que os alunos tenham noções básicas acerca dos conceitos de ambiente físico, de como ele nos afeta e é afetado por nós; que adquiram noções básicas de habilidades sociais; que aprendam três técnicas de APO, como participantes e as aplicando. Há uma maior preferência, por parte das crianças, de que a aplicação seja feita com outras crianças que com funcionários e professores.

A aplicação das técnicas de APO (Walkthrough, Poema dos Desejos e Matriz de Descobertas) pelas crianças pode ter seus resultados divididos em três categorias: foco no ambiente físico; sonhos e foco nos aspectos relacionais.

Os resultados com foco no ambiente físico mostraram a preocupação com a qualidade do ambiente físico da escola. Elas citam os ambientes que mais passam tempo: sala de aula e banheiros, bem como o refeitório e os bebedouros. O tamanho dos espaços, o conforto térmico e o conforto das cadeiras também foram sinalizados como importantes, sendo presenciado durante a execução da atividade o quanto a mudança de temperatura afeta as aulas e que as escolas não estão preparadas para isso.

A falta de aparatos ou o seu não uso também foram identificados. Por exemplo, em uma das escolas não há uma quadra para prática esportiva, enquanto em duas escolas a biblioteca e a sala de informática são pouco utilizadas. É importante, para as crianças, poder aproveitar o que a escola tem para oferecer, Ihes dando a sensação de apropriação da escola. As crianças frequentemente mencionam as áreas verdes, mas, não havendo equipamentos nesses espaços (a exemplo de bancos), o seu uso é comprometido.

Já os resultados categorizados como sonhos trazem, especificamente, o que foi posto em alguns Poemas dos Desejos e tem por objetivo tratar dos sonhos das crianças. O principal sonho é ter uma piscina na escola, área para brincar e trazer o verde para os corredores. O desejo de que houvesse aulas de dança, xadrez e artes marciais também surgiu. Contudo, aqui as crianças não apresentaram apenas seus sonhos, como a reforma ou construção de novos espaços, elas apresentaram preocupações com a limpeza e manutenção dos espaços já existentes. Elas citam os ambientes que mais passam tempo: sala de aula e banheiros bem como o refeitório e os bebedouros. Esses itens tiveram especial atenção pois se direciona para a qualidade dos mesmos e o cuidado em termos de manutenção e uso.

Os resultados com foco nos aspectos relacionais não foram diretamente investigados através das técnicas de APO, mas emergiram de forma robusta. As crianças apontaram a importância de se dar atenção aos aspectos relacionais, que incluem: a relação professor-aluno; coordenação/direçãoaluno, e; criança-criança. Elas percebem que os aspectos relacionais têm tanto impacto na qualidade da experiência na escola quanto os aspectos do ambiente físico.

Algo inesperado foi a percepção para as deficiências da escola quanto à acessibilidade, os alunos foram capazes de notar a ausência de rampas 
adequadas entre os desníveis na $2^{a}$ escola. Enquanto na $3^{a}$ escola eles apontaram a presença de piso tátil por todo o chão da mesma.

Extrapolando o espaço da escola, as crianças citaram a relação escolatrajeto-casa. Apresentaram os aspectos da locomoção até a escola e de volta para casa enfatizando a questão do conforto e da segurança. Assim como também reconhecem aspectos positivos e negativos nas próprias casas e no entorno da escola.

\section{CONSIDERAÇÕES FINAIS}

É possível concluir que as crianças se apropriaram das técnicas para expressar suas impressões a respeito da escola e o que faz a experiência delas no ambiente positiva ou negativa. As crianças participantes do estudo puderam ter mais clareza da relação entre ambiente físico e as relações interpessoais, bem como do papel de cada um na escola.

Os resultados da APO foram analisados pelos pesquisadores e discutidos com os alunos. Sugere-se que as crianças participem também do processo de análise, para que elas aumentem o interesse pelo processo de produção de conhecimento e potencialize a vontade de trazer isso a público apresentando para a comunidade escolar, completando o ciclo científico e favorecendo processos de mudanças dentro da escola.

A proposta do projeto foi operacionalizada em um programa de educação ambiental que dura 10 encontros. Esse formato foi escolhido para que professores do ensino fundamental e médio possam inserir esse conteúdo de forma transversal durante o ano letivo seguindo o que a lei brasileira preconiza. Tem-se a expectativa de que ao se apresentar um conteúdo pronto, que já vem com uma cartilha e com instruções que podem ser encontradas futuramente no site do grupo de pesquisa.

O programa também é inovador ao focar no ambiente físico da escola e sua dinâmica de funcionamento, um ambiente familiar e de fundamental importância para a formação da futura geração. Baseia-se em aspectos inovadores, por focar em uma tarefa que exige participação ativa das crianças e as capacita para as relações interpessoais. Usar a escola como elemento base para a promoção da educação ambiental pode auxiliar em tornar as crianças mais conscientes do seu contexto, com recursos para sua avaliação e negociação social para melhorias. Além disso, é um elemento suficientemente neutro que pode ser trabalhado em diversos ângulos a depender da matéria que esteja sendo enfocada ou seja de responsabilidade do professor.

\section{AGRADECIMENTOS}

Às instituições de fomento: Fapitec (Fundação de Apoio à Pesquisa e a Inovação Tecnológica do Estado de Sergipe), Capes (Coordenação de Aperfeiçoamento de Pessoal de Nível Superior) e CNPq (Conselho Nacional de Desenvolvimento Científico e Tecnológico).

Às instituições de apoio: DESO/SE (Companhia de Saneamento de Sergipe) e SEDUC/SE (Secretaria de Estado da Educação, do Esporte e da Cultura) 


\section{REFERÊNCIAS}

ARDOIN, N. M., et al. Nature-based tourism's impact on environmental knowledge, attitudes, and behavior: a review and analysis of the literature and potential future research. Journal of Sustainable Tourism, 23, 838-858, 2015.

ARDOIN, N. M. et al. Environmental education and K-12 student outcomes: A review and analysis of research. The Journal Of Environmental Education, [s.l.], v. 49, n. 1, p.1-17, 29 set. 2017. Informa UK Limited.

BALCAZAR, F. E.; KEYS, C. B.; KAPLAN, D. L.; SUAREZ-BALCAZAR, Y. Participatory action research and people with disabilities: Principles and challenges.

Canadian Journal of Rehabilitation, 12, 105-112, 1998.

CABALLO, V. E. Manual de avaliação e treinamento das habilidades sociais. São Paulo: Santos, 2006.

CASTRO, R. Educación ambiental. Estrategias para construir actitudes y comportamentos proambientales. Em: ARAGONÉS, J. I.; AMÉRIGO, M. (Orgs). Psicología Ambiental. Espanha: Pirámide, 2010.

CHARATSARI, C.; LIOUTAS, E. D. Environmental education in university schools: A study in a logistics faculty. Applied Environmental Education \& Communication, p. 1-12, 2017.

CIA, F.; BARHAM, E. J. Repertório de habilidades sociais, problemas de comportamento, autoconceito e desempenho acadêmico de crianças no início da escolarização. Estudos de Psicologia, 26(1), 45-55, 2009.

DEL PRETTE, Z. A. P.; DEL PRETTE, A. Habilidades sociais: Uma área em desenvolvimento. Psicologia Reflexão e Crítica, 9(2), 233-255, 1996

FERREIRA, C.S. C. et al. Avaliação pós-ocupação em ambiente destinado à educação infantil: uma abordagem multimétodos. Anais do XI ENTAC, p.11241133, 2006.

FRANÇA, A. J. G. L. Ambientes contemporâneos para o ensino-aprendizagem: Avaliação Pós-Ocupação aplicada a três edifícios escolares públicos, situados na Região Metropolitana de São Paulo. Dissertação de mestrado nãopublicada. Programa de Pós-graduação da Faculdade de Arquitetura e Urbanismo. São Paulo: Universidade de São Paulo, 2011.

FREIRE, P. Pedagogia da Autonomia: saberes necessários à prática educativa. Rio de Janeiro: Paz e Terra, 1997.

GIFFORD, R. Environmental psychology matters. Annual review of psychology. Jan 3; 65, p.541-79, 2014.

GÜNTHER, H.; ROZESTRATEN, R. J. Psicologia ambiental: algumas considerações sobre sua área de pesquisa e ensino. Psicologia: teoria e pesquisa, v. 9, n. 1, p. 109-124, 1993.

KARPUDEWAN, M.; KEONG, C. C. Pro-environmental concern among primary school students. Sains Humanika, v. 63, n. 2, 2012.

KOPNINA, H. Future scenarios and environmental education. The Journal of Environmental Education, v. 45. n. 4, p. 217-231, 2014.

KUDRYAVTSEV, A.; STEDMAN, R. C.; KRASNY, M. E.. Sense of place in environmental education. Environmental education research, 18(2), p. 229-250, 2012. 
LOPES, D. C. et al. Social skills: A key factor for engineering students to develop interpersonal skills. International journal of Engineering Education, v. 31 , n. 1, p. 405-413, 2015.

MERENLENDER, A. M. et al. Evaluating environmental education, citizen science, and stewardship through naturalist programs. Conservation Biology, $v$. 30, n. 6, p. 1255-1265, 2016.

MOREIRA, A. M. C. A competência social de assertividade: estudos no primeiro ciclo do Ensino Básico, Dissertação (Mestrado) - Departamento de Ciências da Educação, Universidade dos Açores, Ponta Delgada, 2016.

ORNSTEIN, S. W. Post-occupancy evaluation in Brazil. Evaluating Quality in Educational Facilities, School of Architecture and Urbanism, USP, São Paulo, 135-143, 2005.

POL, E.; CASTRECHINI, A. Disrupción en la educación para la sostenibilidad? Revista Latinoamericana de Psicologia, v. 45, n. 34, p. 333-347, 2013.

RHEINGANTZ, P. A. et al. Observando a qualidade do lugar: procedimentos para a avaliação pós-ocupação. Rio de Janeiro: Proarq, FAU-UFRJ, 2009.

WALS, A. E. et al. Convergence between science and environmental education. Science, v. 344, n. 6184, p. 583-584, 2014. 